\title{
107. Interaction of Light and Darkness in the Germination of the Light-favored Tobacco Seeds \\ (Preliminary Report)
}

\author{
By Kôshi OGawara \\ College of Education, Okayama University \\ (Comm. by H. KinARA, M.J.A., June 12, 1954)
}

Light effect upon the seed germination constitutes a problem of agricultural as well as scientific interest. Many investigations carried out since the discovery of this peculiar phenomenon in 1860 , indicate that such measures as increased oxygen pressure, daily alternation of temperature and pricking of the seed coats improve more or less the germination of light-favored seeds. Several kinds of nitrate solutions also act as substitutes for the light in some cases, and weak acids decrease the need for light. ${ }^{12)}$ In spite of these investigations which have led M. Kipp ('29) ${ }^{3)}$ to the reasonable hypothesis of a reducing influence of light, it must be admitted that the mechanism of light effect upon the germination of lightfavored seeds is still obscure.

In order to attack the problem, the writer has studied the effect of intermittent light and has obtained results suggesting that the effect of light might be accomplished not only in the light but also in the dark. The preliminary results of this study are reported in this paper.

The writer wishes to acknowledge his indebtedness to Dr. I. Namikawa, Dr. S. Imamura, Dr. R. Takahashi, and Dr. T. Sakamura for their valuable suggestions and criticisms.

\section{Material and Methods}

It is well known that the germination of tobacco seeds is lightfavored. Two varieties, "Bright Yellow" and "Kokubu", were used in the experiments which have been carried out from April to June, 1952 with seeds harvested in the preceding year. The germination tests were made in the following way, with some modifications serving to answer the purpose of the experiments.

One hundred seeds were placed on filter paper set in a petri dish of $9 \mathrm{~cm}$ in diameter and moistened with $5 \mathrm{cc}$ of distilled water. One set for each test consisted of three dishes thus prepared. All the tests were carried out in the dark room. After presoaking 7 days in darkness they were exposed to light, and then allowed to germinate for 7 days more. Two lamps of 20 watts were used for 
illumination, luminosity at the seed surface being adjusted to 100 lux. The germinating temperature was generally kept at $25^{\circ} \mathrm{C}$.

In the present paper, for convenience, the dark period prior to the first illumination, $L_{1}$, is indicated by $D_{1}$, the second illumination by $L_{2}$ and the dark period between $L_{1}$ and $L_{2}$ by $D_{2}$.

\section{Experimental Results}

In order to find out the effect of discontinuance of the light period by the insertion of a dark period, the seeds illuminated for 45 or 15 minutes were placed in the dark for $1 / 6,1 / 2,1,3$ and 5 hours, which was followed by illumination lasting 15 minutes. Control batches were illuminated for 60 or 30 minutes without interruption (Fig. 1).

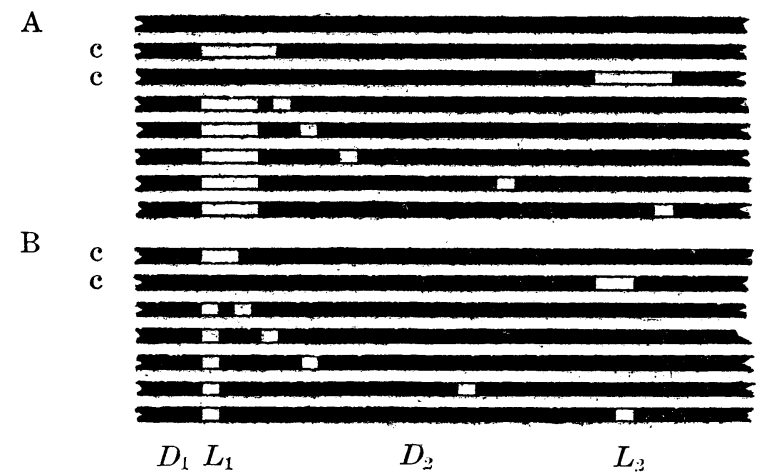

$$
\begin{array}{ll}
\text { A: } & L_{1} 45 \text { minutes, } L_{2} 15 \text { minutes } \\
\text { B: } & L_{1} 15 \text { minutes, } L_{2} 15 \text { minutes } \\
\text { c represents control batch. }
\end{array}
$$

White and black columns show the corresponding length of treatment. The longest white column is 60 minutes.

Fig. 1. Schemata illustrating the method of illumination

The data given in Fig. 2 show that intermittent light promotes the germination of tobacco seeds remarkably, as compared with continuous illumination. The germination percentage increases with the lengthening of the dark period $D_{2}$, inserted between the two periods of illumination. The duration of the first illumination also affects the germination. The longer the first illumination period the higher the percentage.

The relation of the temperature during the dark period $D_{2}$ to germination was indicated by the results of an experiment in which the temperature of the 5 hours' dark period between two light periods of 10 minutes was increased from $0^{\circ} \mathrm{C}$ to $25^{\circ} \mathrm{C}$ by $5^{\circ} \mathrm{C}$-steps, each $5^{\circ} \mathrm{C}$ higher than the preceding one (Table I). 


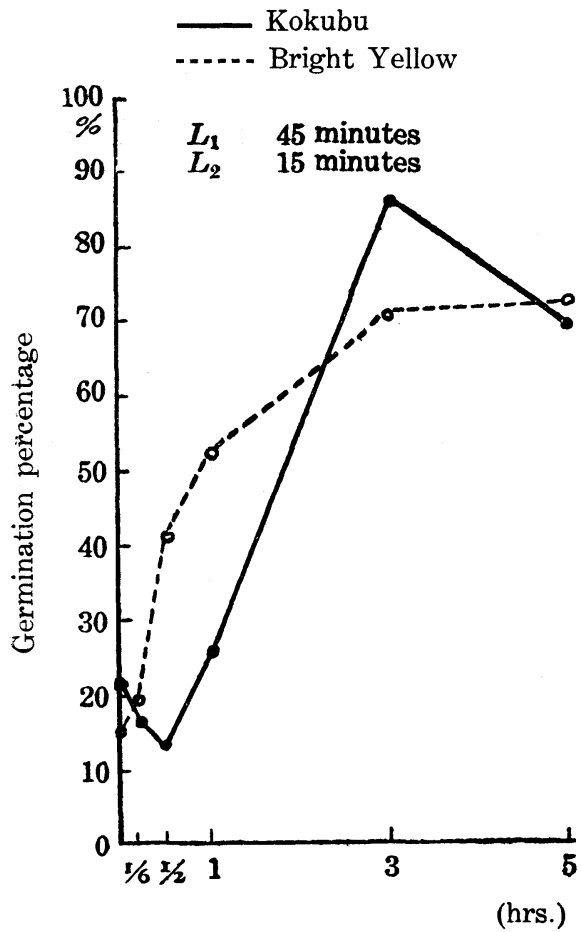

Length of dark period $\left(D_{2}\right)$

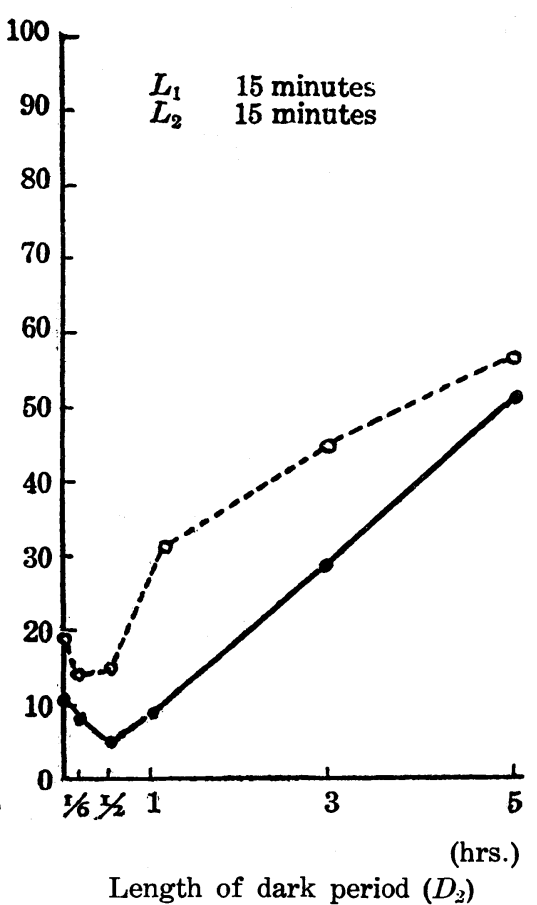

Length of dark period $\left(D_{2}\right)$

Fig. 2. Effect of the length of the dark period $\left(D_{2}\right)$ inserted between two periods of illumination

\section{Table I}

Effect of temperature during the 5 hours' dark period $D_{2}$ between two periods of 10 minutes illumination each

\begin{tabular}{|c|c|c|c|c|c|c|}
\hline $\begin{array}{l}\text { Temperature of } \\
\text { dark period }\end{array}$ & $0^{\circ} \mathrm{C}$ & $5^{\circ} \mathrm{C}$ & $10^{\circ} \mathrm{C}$ & $15^{\circ} \mathrm{C}$ & $20^{\circ} \mathrm{C}$ & $25^{\circ} \mathrm{C}$ \\
\hline Bright Yellow & $14.0 \%$ & $26.7 \%$ & $41.3 \%$ & $42.7 \%$ & $58.0 \%$ & $56.7 \%$ \\
\hline Kokubu & 13.7 & 24.7 & 34.3 & 41.0 & 57.3 & 62.3 \\
\hline
\end{tabular}

Table I shows that the temperature applied during the dark period exerts a considerable influence upon germination. Rise in the temperature during the dark period apparently favors germination. From this fact it is suggested that a reaction taking place in the dark and susceptible to temperature may be involved in the germination of light-favored seeds.

After exposure to light and then to the temperature of $25^{\circ} \mathrm{C}$ for $0,1,3$ and 5 hours, the seeds were transferred to $30^{\circ} \mathrm{C}$ or $0^{\circ} \mathrm{C}$ for 1 hour. It is evident from the data in Table II, that high temperature treatment after the illumination promotes germination, 
while the treatment with low temperature decreases it. The highest and the lowest germination occurred when treatment was applied 1-2 hours after the illumination, probably at the time when the reaction taking place in the dark proceeds most rapidly.

Table II

Effect of 1 hour's treatment with high $\left(30^{\circ} \mathrm{C}\right)$ or low $\left(0^{\circ} \mathrm{C}\right)$ temperature $0-5$ hours after illumination

\begin{tabular}{|c|c|c|c|c|c|c|c|c|}
\hline \multirow[b]{2}{*}{ Treatment } & 40 & nt & \multicolumn{5}{|c|}{ Hours after illumination } & \multirow{2}{*}{$\begin{array}{c}\text { Control } \\
\text { (no tempera- } \\
\text { ture } \\
\text { treatment) }\end{array}$} \\
\hline & & ties & 0 & 1 & 2 & 3 & 5 & \\
\hline $\begin{array}{c}\text { Illuminated } \\
\text { for } 10 \\
\text { minutes }\end{array}$ & $\left|30^{\circ} \mathrm{C}\right|$ & $\begin{array}{l}\text { Bright } \\
\text { Yellow } \\
\text { Kokubu }\end{array}$ & $\begin{array}{l}23.0 \% \\
15.3\end{array}$ & $\begin{array}{l}64.0 \% \\
60.3\end{array}$ & $\begin{array}{l}68.7 \% \\
28.0\end{array}$ & $\begin{array}{l}54.3 \% \\
21.0\end{array}$ & $\begin{array}{l}49.0 \% \\
10.7\end{array}$ & $\begin{array}{l}21.7 \% \\
10.3\end{array}$ \\
\hline $\begin{array}{l}\text { Illuminated } \\
\text { for } 20 \\
\text { minutes }\end{array}$ & $0^{\circ} \mathrm{C}$ & $\begin{array}{l}\text { Bright } \\
\text { Yellow } \\
\text { Kokubu }\end{array}$ & $\begin{array}{l}40.0 \\
36.3\end{array}$ & $\begin{array}{l}35.7 \\
25.7\end{array}$ & $\begin{array}{l}30.3 \\
23.3\end{array}$ & $\begin{array}{l}42.3 \\
31.0\end{array}$ & $\begin{array}{l}43.0 \\
35.7\end{array}$ & $\begin{array}{l}46.7 \\
40.3\end{array}$ \\
\hline
\end{tabular}

The temperature effect during the light period was also investigated. The results of an experiment in which the seeds were illuminated for 10 minutes at the temperatures of $0^{\circ} \mathrm{C}$ to $35^{\circ} \mathrm{C}$ increasing by $5^{\circ} \mathrm{C}$-steps are shown in Table III, which reveals that the temperature during the light period did not affect the germination in this case. Approximately the same germination percentage was obtained at all temperatures tested.

Table III

Effect of temperature during the illumination of 10 minutes

\begin{tabular}{c|c|c|c|c|c|c|c|c}
\hline $\begin{array}{r}\text { Temperature } \\
\text { during the } \\
\text { illumina- } \\
\text { tion }\end{array}$ & $0^{\circ} \mathrm{C}$ & $5^{\circ} \mathrm{C}$ & $10^{\circ} \mathrm{C}$ & $15^{\circ} \mathrm{C}$ & $20^{\circ} \mathrm{C}$ & $25^{\circ} \mathrm{C}$ & $30^{\circ} \mathrm{C}$ & $35^{\circ} \mathrm{C}$ \\
Varieties & & & & & & & & \\
\hline $\begin{array}{c}\text { Bright Yellow } \\
\text { Kokubu }\end{array}$ & $\begin{array}{l}30.7 \% \\
11.0\end{array}$ & $\begin{array}{l}32.7 \% \\
10.0\end{array}$ & $33.3 \%$ & $32.7 \%$ & $33.0 \%$ & $34.0 \%$ & $33.7 \%$ & $32.3 \%$ \\
\hline
\end{tabular}

But another experiment in which the seeds were illuminated for periods of different length gave different results. As represented in Table IV, the influence of the temperature on germination during a long light period was considerable. The germination percentage increases with the lengthening of the light period, but no difference is discernible at high and low temperature at short illumination 
whereas at a longer light period the difference becomes remarkable. It seems therefore that, simultaneously with a light reaction, a reaction susceptible to temperature is taking place when a long continuous illumination is applied.

Table IV

Effect of temperature during light periods of different duration

\begin{tabular}{|c|c|c|c|c|c|c|c|c|c|}
\hline \multirow{2}{*}{ Varieties } & \multirow{2}{*}{$\begin{array}{l}\text { Temperature } \\
\text { during the } \\
\text { illumination }\end{array}$} & \multicolumn{8}{|c|}{ Length of light period (hrs.) } \\
\hline & & 0 & $1 / 12$ & $1 / 6$ & $1 / 2$ & 1 & 2 & 3 & 5 \\
\hline \multirow{3}{*}{$\begin{array}{l}\text { Bright } \\
\text { Yellow }\end{array}$} & & & & & & & & & \\
\hline & $25^{\circ} \mathrm{C}$ & $0 \%$ & $22.0 \%$ & $37.7 \%$ & $78.7 \%$ & $87.3 \%$ & $91.7 \%$ & $\% 93.3 \%$ & $695.7 \%$ \\
\hline & $0^{\circ} \mathrm{C}$ & 0 & 21.7 & 37.3 & 51.0 & 67.3 & 70.3 & 73.3 & 74.3 \\
\hline \multirow[t]{2}{*}{ Kokubu } & $25^{\circ} \mathrm{C}$ & 0 & 12.3 & 15.7 & 39.7 & 80.0 & 83.7 & 84.7 & 88.3 \\
\hline & $0^{\circ} \mathrm{C}$ & 0 & 11.7 & 16.0 & 19.3 & 41.7 & 48.3 & 50.3 & 52.0 \\
\hline
\end{tabular}

It appeared also to be of importance to find out whether the process of dark reaction is indifferent to the influence of light or not. In order to find the effect of interruption of a long continuous illumination by inserting a dark period, other experiments were performed. A five hour illumination was interrupted by a dark period of $1 / 2,1,2$ and 3 hours, so that each lot received in total a 4.5, 4, 3 and 2 hours' illumination respectively. No interruption by a dark period was given to one batch serving as control. Table $\mathrm{V}$ shows that the insertion of a dark period into the long light period promotes the germination in spite of the curtailment of the total illumination. The germination was best when the inserted dark period lasted 2 hours. But when the dark period was lengthened to 3 hours, it decreased perhaps due to insufficient illumination.

Table V

Effect of dark periods inserted in a long continuous illumination

\begin{tabular}{|c|c|c|c|c|c|c|c|c|c|}
\hline \multirow{2}{*}{$\begin{array}{l}\text { Illumination } \\
\text { method }\end{array}$} & \multicolumn{5}{|c|}{$\begin{array}{l}\text { Length of dark and light periods } \\
\text { in hr. }\end{array}$} & \multicolumn{4}{|c|}{$\begin{array}{l}\text { Single continuous illumina- } \\
\text { tion in } \mathrm{hr} \text {. }\end{array}$} \\
\hline & $\begin{array}{ll}L_{1} & 2.5 \\
D_{2} & 0 \\
L_{2} & 2.5\end{array}$ & $\begin{array}{l}2.25 \\
0.5 \\
2.25\end{array}$ & $\begin{array}{l}2 \\
1 \\
2\end{array}$ & $\begin{array}{l}1.5 \\
2 \\
1.5\end{array}$ & $\begin{array}{l}1 \\
3 \\
1\end{array}$ & 4.5 & 4 & 3 & 2 \\
\hline Bright Yellow & $42.3 \%$ & $54.3 \%$ & $58.0 \%$ & $61.3 \%$ & $51.0 \%$ & $39.7 \%$ & $38.3 \%$ & $34.7 \%$ & $28.0 \%$ \\
\hline Kokubu & 54.7 & 72.0 & 75.3 & 81.7 & 65.3 & 52.0 & 43.0 & 34.7 & 30.3 \\
\hline
\end{tabular}

Also the effect on germination of interruption of dark period $D_{2}$ by exposure to light of short duration was investigated. The seeds were illuminated twice for 1.5 hours, and the 2 hours' dark period $D_{2}$ was interrupted by another short light period of $1,2,3,5$ and 10 minutes. Illumination was uninterrupted in a control batch. 
The results shown in Table VI revealed that the interruption of the dark period lowered the germination percentage. From these results it seems that the dark reaction may proceed more readily in the dark than in the light.

\section{Table VI}

Effect of interruption of the dark period $\left(D_{2}\right)$ of two hours by insertion of a short light period. $L_{1}$ and $L_{2} 1.5$ hours each

\begin{tabular}{c|c|c|c|c|c|c}
\hline & \multicolumn{6}{|c|}{ Light period inserted in $D_{2}(\min )}$. \\
Varieties & 0 & 1 & 2 & 3 & 5 & 10 \\
\hline Bright Yellow & $59.7 \%$ & $59.3 \%$ & $60.7 \%$ & $51.3 \%$ & $48.3 \%$ & $46.7 \%$ \\
Kokubu & 83.3 & 84.7 & 79.7 & 71.3 & 70.7 & 68.3
\end{tabular}

Discussion

The physiological responses of light-favored seed are complicated and difficult of interpretation. Formerly, the action of light on the seed germination was thought to be a stimulus response. In the present status, it seems much more probable that light brings about chemical and physical changes which result in germination. Furthermore, the present results of experimenting with the dark reaction seem to give another explanation to this problem.

The germination of tobacco seeds is promoted by the action of intermittent light as compared with continuous illumination. The germination rate promoted by the dark period inserted between two illuminations increases when the dark period becomes longer. On the other hand, however long the dark period may be, a remarkable increase cannot be expected when the first illumination is too short. It seems necessary for the highest germination that the seeds should be subjected to the influence of sufficiently long periods of light and darkness. These results suggest the occurrence of the reactions of light and dark in the light-favored tobacco seeds similar to other physiological phenomena related to light such as photosynthesis and photoperiodism. The dark reaction was proved, in contrast to the light reaction, to be associated with relatively high temperature. The promoting effect of intermittent light was determined by the interaction of these two processes. The results also provided the evidence of the simultaneous occurrence of both light and dark reactions during the long light period and showed that the dark reaction proceeds more readily in the absence of light.

\section{References}

1) Crocker, W.: Growth of Plants. New York (1948).

2) Crocker, W. and Barton, L. A.: Physiology of Seeds. Waltham (1953).

3) Kipp, M.: Jahrb. wiss. Bot., 71, 533-595 (1929). 